Research paper

\title{
Emergency department waiting room nurse role: A key informant perspective
}

\author{
Kelli Innes ${ }^{\mathrm{a}, \mathrm{c}, *}$, Debra Jackson ${ }^{\mathrm{b}}$, Virginia Plummer ${ }^{\mathrm{c}, \mathrm{d}}$, Doug Elliott ${ }^{\mathrm{a}}$ \\ a Faculty of Health, University of Technology Sydney, Australia \\ b Oxford University Hospitals NHS Foundation Trust, Faculty of Health and Life Sciences, Oxford Brookes University, United Kingdom \\ ${ }^{c}$ Faculty of Medicine, Nursing and Health Sciences, Monash University, Australia \\ d Peninsula Health, Hastings Road Frankston, 3199, Australia
}

\section{A R T I C L E I N F O}

\section{Article history:}

Received 16 June 2016

Received in revised form 8 December 2016

Accepted 8 December 2016

\section{Keywords:}

Emergency departments

Key informants

Waiting room

Emergency nursing

Patient safety

Interview

\begin{abstract}
A B S T R A C T
Background: Emergency departments have become overcrowded with increased waiting times. Strategies to decrease waiting times include time-based key performance indicators and introduction of a waiting room nurse role. The aim of the waiting room nurse role is to expedite care by assessing and managing patients in the waiting room. There is limited literature examining this role.

Methods: This paper presents results of semi-structured interviews with five key informants to explore why and how the waiting room nurse role was implemented in Australian emergency departments. Data were thematically analysed.

Results: Five key informants from five emergency departments across two Australian jurisdictions (Victoria and New South Wales) reported that the role was introduced to reduce waiting times and improve quality and safety of care in the ED waiting room. Critical to introducing the role was defining and supporting the scope of practice, experience and preparation of the nurses. Role implementation required champions to overcome identified challenges, including funding. There has been limited evaluation of the role.

Conclusions: The waiting room nurse role was introduced to decrease waiting times and contributed to risk mitigation. Common to all roles was standing orders, while preparation and experience varied. Further research into the role is required.
\end{abstract}

C 2016 College of Emergency Nursing Australasia. Published by Elsevier Ltd. All rights reserved.

\section{Introduction}

Hospital emergency departments (EDs) continue to face challenges including increasing patient presentations [1], an aging population [2] and limited resources [1]. As a result EDs have become overcrowded and waiting times have increased, contributing to poor patient outcomes [3] and poor patient and family experiences in the ED [4]. To decrease waiting times a number of strategies have been introduced including time-based key performance indicators (KPIs) and the introduction of a waiting room nurse role [5].

KPIs relating to waiting times include overall length of stay in ED and time from triage to treatment. The National Emergency Access Target (NEAT) requires that $90 \%$ of patients are transferred or discharged from the ED within four hours of arrival [5]. Time from triage to treatment is measured against a patient's clinically rele-

\footnotetext{
* Corresponding author at: McMahon's Road, Frankston, Victoria, 3199. Australia. E-mail address: kelli.innes@monash.edu (K. Innes).
}

vant waiting time, as determined by their triage category. Triage categories indicate urgency of care, based on the patient's presenting condition [6]. The process of allocating a triage category is referred to as a primary triage decision. Secondary triage decisions relate to initiating patient care and patient disposition, for example providing analgesia or commencing investigations [7]. In Australia, the five tier Australasian Triage Scale (ATS) is used to allocate triage categories [8]. The KPI requires a percentage of patients within each category to be seen within the allocated time. For example the Category $3 \mathrm{KPI}$ requires that $75 \%$ of patients in this category must be seen within $30 \mathrm{~min}[9]$.

Decreasing waiting times is a focus of the waiting room nurse role. The nurse in this role provides care for patients in the ED waiting room after triage. Aims of the role are to assess and monitor the condition of patients' in the ED waiting room, commence interventions early, detect clinical deterioration and improve communication between patients, families and staff [10].

There is however, a paucity of literature in relation to the impact of waiting room nurse roles on patient outcomes and ED workflow and performance. Existing literature identified a lack of clarification 
about the role, and the support required to make the role effective [10]. The scope of the role has been defined by standing orders, clinical guidelines and pathways [11] which guide decision making [12]. Those undertaking the role were reported to need effective interpersonal communication skills with patients and staff $[12,13]$. While nurses reported that the role improved patient care and outcomes [11,14], there was limited evidence to support that the role improved patient outcomes [10], as waiting times and patient length of stay [12] did not decrease [11]. Understanding why the role was first conceived and introduced is an important initial step in the evaluation of the implementation and effectiveness of the role.

\section{Materials and methods}

This paper presents the results of a study exploring why and how the waiting room nurse role was implemented in Australian EDs.

\section{Design and sample}

An exploratory approach using key informants was used to address the aim. Exploratory designs enable exploration of a phenomenon when little is known about it $[15,16]$, in this case introduction of waiting room nurse roles. Key informants are individuals with a high level of knowledge and/or engagement with the topic of interest, and are respected as being experts in the field. Purposive sampling was therefore used to recruit key informants [17] relevant to the waiting room nurse role. The authors consulted with emergency nurse leaders in key positions in the College of Emergency Nursing Australasia (CENA), the peak professional body representing emergency nurses in Australia [18], and reviewed published literature on the phenomenon to identify six key informants. They held positions of authority and had experience in implementing a waiting room nurse role into an ED, and accordingly could provide an insider view of role need and development, with reflection and in-depth insight into the phenomenon $[19,20]$.

\section{Ethical considerations}

This study adhered to the National Statement on the Conduct of Human Research by the Australian National Health and Medical Research Council and was approved by the supporting university Human Research and Ethics Committee. Key informants were recruited via publically available email addresses. Written informed consent was obtained.

\section{Data collection}

Initially six key informants were approached for involvement, and five consented to participate. Data saturation was achieved within this sample and no further interviews were required [21]. Interviews were undertaken by the first named author and audio-taped. Three interviews were face to face, in a location convenient to the key informant, while two were conducted by phone.
Interview duration ranged from 13 to $41 \mathrm{~min}$ (average $25 \mathrm{~min}$ ). Participants were asked to clarify meaning of responses during the interview.

Semi-structured interviews were conducted using an interview guide. The interview guide consisted of six open-ended questions used to seek clarification, explore previous answers and ensure that the research aim was met [17]. This format allowed for uninterrupted responses from key informants [22]. The trigger questions were: (i) what were the reasons for ED waiting room nurse role being implemented?; (ii) who performs/ed the role; their level of nursing and emergency nursing experience and educational preparation (formal and informal)?; (iii) were there any specific preparations prior to commencing in the role (e.g. orientation)?; (iv) what are/were the responsibilities and skills to be undertaken?; (v) were there any underpinning protocols/governance?; and (vi) was any evaluation of the role performed? Prompts were used to refocus key informants where necessary.

\section{Data analysis}

Interviews were transcribed verbatim and responses deidentified. Transcripts were analysed separately using thematic analysis, to systematically classify data into categories and then themes representing similar meanings. Transcripts were repeatedly read as a whole so that researchers immersed themselves in the data. Exact words or phrases were then highlighted and assigned codes, as transcripts were re-read word for word to identify emerging concepts. Categories were identified from the codes as relationships and links were recognised [23,24]. This approach enabled a detailed understanding of key informants' perceptions and experiences of implementing the role $[23,25]$. Emerging categories and themes were then discussed by the research team until consensus was achieved $[26,27]$. Each key informant was sent a copy of their own interview transcript and a summary of the results, enabling them to provide feedback, clarify points, question interpretations and present alternate reasons or opinions [28].

\section{Results}

The five key informants were experienced emergency nurses who participated in policy development and implementation of an ED waiting room nurse role. Their professional backgrounds varied across education, ED management and hospital management from five metropolitan EDs in two Australian states (Victoria and New South Wales). Key informants all had more than 10 years of ED experience, and held positions as Unit Manager, Clinical Nurse Consultant, Nurse Educator, Practice Development Leader or Practice Development Nurse during implementation of a waiting room nurse role in their ED.

From the interview data, seven categories (Table 1) were identified which were then merged into five themes (Table 2): Expedite care; Three pillars of introduction; Funding sources; Challenges to implementation; and Evaluating the benefit. These themes are discussed below, with de-identified direct quotes used as exemplars or to clarify issues (for example narrative from the first key informant interview is reported as KI 1).

Table 1

Identified categories.

\begin{tabular}{|c|c|c|c|c|c|c|c|}
\hline & Patient Safety & Scope of Practice & Experience & Preparation for the Role & Funding & Role Conflict & Evaluation \\
\hline KI 1 & $\sqrt{ }$ & $\sqrt{ }$ & $\sqrt{ }$ & $\sqrt{ }$ & $\sqrt{ }$ & $\sqrt{ }$ & $\sqrt{ }$ \\
\hline KI 2 & $\sqrt{ }$ & $\sqrt{ }$ & $\sqrt{ }$ & $\sqrt{ }$ & $\mathrm{x}$ & $\sqrt{ }$ & $\sqrt{ }$ \\
\hline KI 3 & $\sqrt{ }$ & $\sqrt{ }$ & $\sqrt{ }$ & $\sqrt{ }$ & $\mathrm{x}$ & $\mathrm{x}$ & $\sqrt{ }$ \\
\hline KI 4 & $\sqrt{ }$ & $\sqrt{ }$ & $\sqrt{ }$ & $\sqrt{ }$ & $\sqrt{ }$ & $\sqrt{ }$ & $\sqrt{ }$ \\
\hline KI 5 & $\sqrt{ }$ & $\sqrt{ }$ & $\sqrt{ }$ & $\mathrm{x}$ & $\sqrt{ }$ & $\mathrm{x}$ & $\sqrt{ }$ \\
\hline
\end{tabular}


Table 2

Identified Themes.

\begin{tabular}{|c|c|c|c|c|c|c|c|}
\hline & Patient safety & Scope of practice & Experience & Preparation for the role & Funding & Role conflict & Evaluatior \\
\hline Expedite care & $\sqrt{ }$ & $\mathrm{x}$ & $\mathrm{x}$ & $\mathrm{x}$ & $\mathrm{x}$ & $\mathrm{x}$ & $\mathrm{x}$ \\
\hline Three pillars of introduction & $\mathrm{x}$ & $\sqrt{ }$ & $\sqrt{ }$ & $\sqrt{ }$ & $\mathrm{x}$ & $\mathrm{x}$ & $\mathrm{x}$ \\
\hline Funding sources & $\mathrm{x}$ & $\mathrm{x}$ & $\mathrm{x}$ & $\mathrm{x}$ & $\sqrt{ }$ & $\mathrm{x}$ & $\mathrm{x}$ \\
\hline Challenges to implementing & $\mathrm{x}$ & $\mathrm{x}$ & $\mathrm{x}$ & $\mathrm{x}$ & $\mathrm{x}$ & $\sqrt{ }$ & $\mathrm{x}$ \\
\hline Evaluating the benefit & $\mathrm{x}$ & $\mathrm{x}$ & $\mathrm{x}$ & $\mathrm{x}$ & $\mathrm{x}$ & $\mathrm{x}$ & $\sqrt{ }$ \\
\hline
\end{tabular}

\section{Expedite care}

Providing a nurse in the waiting room to expedite patient care, in particular decreasing waiting times. Prior to the introduction of the waiting room nurse role, triage nurses performed both primary and secondary triage activities, including initiating analgesia, pathology and radiography requests. These secondary activities contributed to delays as the triage nurse was often "too busy triaging and actually couldn't [attend to secondary triage]" (KI 3) requirements. Key informants reported that patients could often spend extended periods in the waiting room, "at times ... waiting 8, 10 or 12 hours ... it just seemed unreasonable that any consumer would wait to have a service provided" (KI 1). The aim of the waiting room nurse was primarily to mitigate against risk, and improve the safety and quality of care delivery. Participants identified that there "were very unwell patients sitting in the waiting room for an extended period of time" (KI 2). Extended waiting times were considered to pose the greatest risk to care and safety, so the waiting room nurse role "was introduced as a strategy to reduce time to investigations and treatment, reduce length of stay and promote a collaborative approach to emergency care" (KI 3) and to "assess, monitor, [and] intervene if appropriate" (KI 1).

With the potential for patients' clinical condition to deteriorate, re-assessment of waiting patients was identified as a key component of the role. The waiting room nurse needed to be able to "come back and reassess to make sure that their interventions had been appropriate" (KI 1) and "identify the deteriorating patient" (KI 2).

Prior to introduction of the role, extended waiting times resulted in some patients being redirected from the ED to seek care at an alternate health care provider, such as a general practitioner. The key informants reflected that on occasions, these patients were not triaged, and likely not assessed. A number of these "patients were actually quite unwell" (KI 4) and required care in the ED. Redirecting patients to external services placed the patients at risk of adverse outcomes. Risk mitigation, through preventing adverse patient outcomes, was therefore a focus of the waiting room nurse role.

Risk mitigation was also reflected in time related KPIs. Key informants reported that prior to the role being introduced, ED staff were finding the performance indicators difficult to meet, in particular, the Category 3 KPI. The "KPI for Category 3 patients was sitting in the 50\% [range]" (KI 4), demonstrating increased waiting times and potentially compromising patient care and safety. Introduction of the role allowed care for Category 3 patients to commence in the waiting room. Waiting room nurses "start[ed] work on the category 3 [patients], commenced procedures, to speed up the patient journey so [patients] don't have a long wait" (KI 5). This contributed to Category 3 patients "being seen within their allotted 30 min" (KI 5).

\section{Three pillars of introduction}

Key informants reported that there were three key pillars to enabling the smooth introduction of the waiting room nurse role: defining and supporting the scope of practice, selecting nurses with appropriate experience and expertise, and preparing nurses to fulfil the role. It was imperative that the waiting room nurse role be clearly defined. In defining the waiting room nurse role, key informants described how the role differed from that of the triage nurse and the Nurse Practitioner. Key informants reported that the waiting room nurse was essentially responsible for all secondary triage activities, as well as reassessment of patients in the waiting room, "it was a role that was about trying to do the secondary assessment, the post-triage assessment, and then try and identify treatment pathways for those patients, which included nurse initiated X-ray, nurse initiated pathology, analgesia, and ideally then to get those second and potentially third reassessments done in the waiting room". To this end, key informants reported that waiting room nurses required a "range of extended activities" (KI 1).

All key informants identified that standing orders underpinned the extended practices performed by the waiting room nurse. In one ED, nurse initiated policies were written in collaboration with a multidisciplinary team including emergency physicians, ED directors, pharmacy and radiology staff. Another ED developed specific "Category 3 pathways" (KI 4) for the waiting room nurse to initiate interventions when these patients could not be moved directly into a treatment space. Similarly, another ED adapted a manual of clinical pathways from an interstate hospital to meet the particular needs of their department; "each pathway had some key [patient] history points, assessment features like red flags and guidelines around pathology and potential medications" to be administered (KI 2). In this model "medications were all nurse-facilitated" (KI 3), meaning "the emergency physician still had to order the medications" (KI 3). Overall, nurse initiated policies included medications such as analgesia and intravenous fluids; procedures including specific pathology and $\mathrm{x}$-ray requests; and management of presenting conditions including chest pain and shortness of breath. The skill set for nurses undertaking the role included basic life support, cannulation, recording and interpreting electrocardiogram, patient assessment and venepuncture.

Preparation for the role varied across sites. A multidisciplinary model of education was introduced in one ED to upskill staff prior to commencing in the role, using an "in-house" approach "provided by the emergency physicians, [emergency] nurses, educators and other disciplines such as surgeons and radiologists" (KI 1). Workshops including scenarios to discuss clinical pathways, any potential clinical risk and communication including "patient satisfaction, effective communication and therapeutic relationships" (KI 3) were used in another ED. The workshops also covered "the role, the Clinical Nurse Specialist role, and the Nurse Practitioner role and how they were different" (KI 3), as well as "Nurses Board scope of practice guidelines that were in place at the time [and] . . the Drugs and Poisons Legislation" (KI 3). No formal preparation was provided in one ED, based on the premise that nurses undertaking the role were working within "their [Registered Nurse] current scope of practice" (KI 5).

There were varied views on the level of experience required by those performing the role, with the only consensus being that the position required a Registered Nurse (RN) skill set. The majority of key informants identified that the role required an experienced RN who did not necessarily need triage preparation; that is "not really junior, ... some experience” (KI 2); “didn't necessarily have to be a highly experienced nurse ... somebody capable of doing some interventions without requiring assistance" (KI 5) and "didn't necessarily 
have triage experience, but needed to be a senior decision-maker and be able to work autonomously" (KI 4). One key informant stated that they "preferred that the waiting room nurse could not triage, so that they were not tempted to fall back into that role" (KI 4). Conversely, one setting required a "postgraduate prepared emergency nurse with the level of decision-making required of triage nurses" (KI 3).

Level of experience was linked to efficacy of the role. Less experienced nurses "didn't see as many patients quite as quickly" (KI 2). Ensuring that the "right people were in the role" (KI 5) was also important for effective communication. The role was identified as being "ideal to facilitate good communication" with those in the waiting room (KI 5) and the multidisciplinary team in the ED. The waiting room nurse needed to be able to communicate with the "nurse in charge if they felt that the patient needed to come ... into a [treatment] area" (KI 2) and "liaise with the triage nurse" (KI 2) if they felt the patient's condition had changed. Effective communication with medical staff was also identified as a key skill.

\section{Funding sources}

Key informants reported that initially, there was no funding to support the waiting room nurse role, and therefore was resourced by "internal funding" (KI 5) from existing local hospital and ED budgets, and which "was not necessarily ongoing funding" (KI 5). The significance of the role was highlighted in the late 2000's when the New South Wales State Government allocated additional specific funding for the role. One participant noted that the "initiative was brilliant in providing resources to actually make and sustain the model" (KI 1). In Victoria, funding for the role did not change and remained the responsibility of the ED and healthcare networks. Despite a lack of dedicated funding for the waiting room nurse role, it continued in a number of departments due to the leadership and vision of ED managers and advocates.

\section{Challenges to implementing}

Challenges identified with implementing the role, included role confusion and conflict within both the nursing team and the multidisciplinary team. In one model, despite the expectation that the triage nurse and the waiting room nurse "would work in synergy with each other" (KI 5), some conflict was identified. This seemed to arise as a result of a 'waiting room nurse list', which the triage nurse completed to inform the waiting room nurse of any care needs identified during the triage process. The intention of the list was to improve communication, and therefore patient care and outcomes, however, some waiting room nurses "felt that the triage nurse was telling them how to do their job" (KI 4) when using this list.

Role confusion was also identified, in particular, around where triage finished and subsequent emergency care began. There was a perception that "most emergency nurses [understand] where triage stops and emergency care begins" (KI 3). Medical staff were identified as often not understanding the role, particularly in relation to the difference between primary and secondary triage activities. Medical staff were reported to direct requests for secondary triage activities to the triage nurse, rather than the waiting room nurse. To address this, one key informant described aspects of work undertaken was to ensure the role was "acceptable to medical staff" (KI 1).

\section{Evaluating the benefit}

Limited evaluation of the role had been undertaken. Monitoring "as opposed to any formal evaluation" (KI 5) occurred in three EDs, and it was reported that "Category 3 patients [were] seen in a more timely manner" (KI 2). One ED reviewed the number of patients who left before being seen by a medical practitioner (recorded as 'did not wait'), and found "no reduction" (KI 4). This was attributed to the fact that "did not waits traditionally [occurred] later in the night and overnight" (KI 4) when the waiting room nurse role was not operational. Studies examining nurse initiated diagnostics and treatment, and the waiting room nurse role compared to other advanced practice roles in ED were reportedly undertaken at two sites.

\section{Discussion}

This study provided an insight into the introduction of a waiting room nurse role, from the perspective of key informants involved in the initial implementation of the role in five metropolitan EDs across Victoria and New South Wales. Findings demonstrated that the role was introduced to mitigate risk and improve the quality and safety of patient care by expediting care delivery in ED waiting rooms. The use of standing orders to guide practice were common at each site, although preparation for the role and level of experience varied. Implementation challenges included role conflict and confusion, as well as funding sources.

Unreasonable waiting times, risk of adverse events and meeting ED performance KPIs were reasons identified for implementing the role. While one aim of implementing the role was to expedite care and therefore limit length of stay for patients presenting to the ED, there was no evidence from the key informants that this was formally evaluated. However, it is well documented in the literature that increased waiting times are associated with increased length of stay, patient deterioration and increased mortality [29-32]. One group of particular concern, as highlighted by key informants, was Category 3 patients ('urgent'; to be seen within $30 \mathrm{~min}$ of arrival, may be clinically unstable with potentially life threatening conditions) [8]. Category 1 patients (immediately life threatening condition, need to be seen immediately) [8] and Category 2 patients (critically ill, need to be seen within $10 \mathrm{~min}$ of arrival) [8] are generally transferred directly into the treatment areas. During busy periods, this may result in Category 3 patients being left waiting for a treatment space, despite having a potentially life threatening condition. Without frequent re-assessment, deterioration in this group of patients may not be detected until the patient is critically unwell. The waiting room nurse role can potentially identify patient deterioration earlier, playing a role in risk management and risk mitigation in the ED waiting room [33]. Further research is therefore required on the effect the role has on waiting times and risk mitigation.

Variation in experience, preparation, roles and responsibilities were described by key informants at the different sites. This was also found in the wider literature with experience ranging from a minimum two years emergency nursing experience and completion of an orientation program, through to being a post graduate prepared triage nurse with advanced assessment and conflict resolution skills [10]. Of note, there was no evidence of a standardised approach for preparing nurses for the role in the literature. Local policy determined all aspects of the role including title, with some settings referring to the role as the Clinical Initiative Nurse (CIN). These findings were similar to published literature [10].

Interestingly, key informants commonly used the terms advanced practice and extended practice when referring to the role. This ambiguity in terminology is also identified in the literature due to the absence of clear and concise definitions [10]. There is no defined level of experience or educational qualification for the waiting room nurse role. Further research is therefore required to determine the level of experience and preparation required of those undertaking the role to maximise efficacy and risk mitigation.

One of the challenges to the introduction of the waiting room nurse role, was the role conflict generated both between the triage nurse and waiting room nurse, and between disciplines. This was 
evident prior to implementation, when a key informant identified that the role had to be acceptable to medical staff and did not encroach on their roles and responsibilities. This concept, known as 'territoriality', occurs when individuals, professions or organisations defend their area of responsibility (territory) against a perceived threat $[34,35]$. Territoriality can result in a power struggle that sees limited resources and energy used to fight against each other, rather than collaborating and working together to achieve a common goal $[34,35]$. The solution to these conflicts was to ensure the role was developed in collaboration with other members of the ED team. This was evidenced by the use of a multidisciplinary approach to write policy and educate nurses prior to commencing the role.

While evaluation is key to establishing the effect of the role on quality of care and safety for patients in the waiting room, limited formal evaluation had been undertaken. This was also reflected in the published literature where study designs and methods varied [10]. There is a need for further research evaluating the scope and effect of the waiting room nurse role.

\section{Study strengths and limitations}

A number of strengths and limitations are noted. Data saturation was achieved within the sample size. Although duration of the interviews was relatively short, adequate time and use of silence was provided to enable considered responses. Trustworthiness of the research was established through trust value, applicability, consistency and neutrality $[26,27]$. Trust value was undertaken through member checking, specifically obtaining feedback from the key informants, on the findings to ensure that data had been interpreted correctly $[26,27]$. Applicability was achieved as rich, descriptive data was provided allowing for comparison [26,27]. Consistency was achieved as all data from key informants was included in the findings, given equal weighting [28] and emerging themes were discussed within the research team [26,27]. Finally, neutrality was achieved as bias was considered by the researchers $[26,27]$. Investigator bias was considered; to prevent hypotheses confirmation bias, the interviewer set out to maintain an objective position, and conclusions were drawn from consensus within the research team [28]. Consistency and coherence was evident from key informant responses, limiting any risk of bias. To decrease elite bias and concrete bias, responses were re-examined to ensure that an emphasis was not placed on any specific key informant [28]. Finally, there was no attempt to compare how the role currently operates or varies across jurisdictions, including title, scope of practice or underlying policy.

\section{Conclusion}

Key informants identified the reasons for introducing a waiting room nurse role. Key informants identified that the role was introduced to provide safe, quality care in ED waiting rooms and potentially play an important role in risk mitigation. Standing orders and policies were consistently used to define the scope of the role. However, preparation for the role, and the level of experience required, varied. In implementing the role emergency nursing leaders faced challenges of role conflict and confusion, and a lack of funding. Key informants reported limited formal evaluation of the role.

Based on these findings and the related literature, further research into this role is needed. Recommended topic areas include the extent to which the role is utilised in the clinical setting, including any variations within or across jurisdictions; patient and relative perspectives on the role; the impact the role has had on patient waiting times; and examination of KPIs and risk mitigation.

\section{Authorship}

KI, DE, DJ and VP conceived and designed the study. KI conducted the interviews and extracted the data. DE, DJ and VP reviewed transcripts. KI prepared manuscript and DE, DJ and VP contributed to its revision.

\section{Provenance and conflict of interest}

The authors declare that they have no competing interests.

\section{Funding}

This research received no specific grant from any funding agency in the public, commercial, or not-for-profit sectors.

\section{References}

[1] Di Somma S, Paladino L, Vaughan L, Lalle I, Magrini L, Magnanti M. Overcrowding in emergency department: an international issue. Intern Emerg Med 2015;10(2):171-5.

[2] Hwang U, Shah MN, Han JH, Carpenter CR, Siu AL, Adams JG. Transforming emergency care for older adults. Health Aff 2013:32(12):2116-21.

[3] Bernstein SL, Aronsky D, Duseja R, Epstein S, Handel D, Hwang U, et al. The effect of emergency department crowding on clinically oriented outcomes. Acad Emerg Med 2009;16(1):1-10.

[4] Dinh MM, Enright N, Walker A, Parameswaran A, Chu M. Determinants of patient satisfaction in an Australian emergency department fast-track setting. Emerg Med J 2013;30(10):824-7

[5] Crawford K, Morphet J, Jones T, Innes K, Griffiths D, Williams A. Initiatives to reduce overcrowding and access block in Australian emergency departments: a literature review. Collegian 2014;21(4):359-66.

[6] Australasian College for Emergency Medicine. Guidelines on the implementation of the Australasian triage scale in emergency department. Australian College of Emerency Medicine; 2013. November 2013. Report No. 4.

[7] College of Emergency Nursing Australasia. Position Statement - Triage and the Australasian Triage Scale 2015 [cited 2016 29th May]. position Statement]. Available from:

http://www.cena.org.au/wp-content/uploads/2014/10/Position-StatementTriage-and-the-Australasian-Triage-Scale.pdf.

[8] Australasian College of Emergency Medicine. Guidelines on the implementation of the Australasian triage scale in emergency departments West Melbourne Australasian College of Emergency Medicine; 2013 [cited 2016 15th March]. Available from:

https://www.acem.org.au/getattachment/d19d5ad3-e1f4-4e4f-bf837e09cae27d76/G24-Implementation-of-the-Australasian-Triage-Scal.aspx.

[9] Sibbritt D, Isbister GK, Walker R. Emergency department performance indicators that encompass the patient journey. Qual Manage Health Care 2006;15(1):27-38.

[10] Innes K, Jackson D, Plummer V, Elliott D. Care of patients in emergency department waiting rooms - an integrative review. J Adv Nurs 2015;71(12):2702-14.

[11] Fry M, Jones K. The clinical initiative nurse: extending the role of the emergency nurse, who benefits? Australasian Emerg Nurs J 2005;8(1-2):9-12.

[12] Considine J, Lucas E, Payne R, Kropman M, Stergiou HE, Chiu H. Analysis of three advanced practice roles in emergency nursing. Australasian Emerg Nurs J 2012;15(4):219-28

[13] Fry M, MacGregor C, Ruperto K, Jarrett K, Wheeler J, Fong J, et al. Nursing praxis, compassionate caring and interpersonal relations: an observational study. Australasian Emerg Nurs J 2013;16(2):37-44.

[14] Fry M, Ruperto K, Jarrett K, Wheeler J, Fong J, Fetchet W. Managing the wait: clinical initiative nurses' perceptions of an extended practice role. Australasian Emerg Nurs J 2012;15(4):202-10.

[15] Cooper S, Porter J, Endacott R. Mixed methods research: a design for emergency care research? Emerg Med J 2011;28(8):682-5.

[16] Creswell J, Plano Clark V. Designing and Conducting Mixed Methods Research. 2nd ed. Singapore: Sage Publications; 2011

[17] Schneider Z, Whitehead D, Lobiondo-Wood G, Haber J. Nursing and midwifery research methods and apparaisal for evidence-based practice. 5 th ed. NSW: Elsevier; 2016.

[18] College of Emergency Nursing Australasia. College of Emergency Nursing Australasia 2016 [cited 2016 15th March]. Available from: http://www.cena.org.au/.

[19] Marshall MN. The key informant technique. Fam Pract 1996;13(1):92-7.

[20] Kim JR, Elliott D, Hyde C. The influence of sociocultural factors on organ donation and transplantation in Korea: findings from key informant interviews. J Transcult Nurs 2004;15(2):147-54. 
[21] Guest G, Bunce A, Johnson L. How many interviews are enough? an experiment with data saturation and variability. Field Methods 2006;18:59-82.

[22] Taylor B, Francis K. Qualitative research in the health sciences: methodologies, methods and processes. 1st ed. Great Britain: Routledge; 2013, 297.

[23] Hsieh HF, Shannon SE. Three approaches to qualitative content analysis. Qual Health Res 2005;15(9):1277-88.

[24] Moretti F, van Vliet L, Bensing J, Deledda G, Mazzi M, Rimondini M, et al. A standardized approach to qualitative content analysis of focus group discussions from different countries. Patient Educ Couns 2011;82(3):420-8.

[25] Essentials of Nursing Research; Appraising evidence for nursing practice.Polit D, Beck C, editors. 4th ed. Sydney, Australia: Lippincott Williams \& Wilkins; 2014.

[26] Krefting L. Rigor in qualitative research: the assessment of trustworthiness. Am J Occup Ther 1991;45(3):214-22.

[27] Noble H, Smith J. Issues of validity and reliability in qualitative research. EvidBased Nurs 2015;18(2):34-5.

[28] Kumar K. Conducting key informant interviews in developing contries. Center for Development Information and Evaluation A.I.D; 1989
[29] Scott BM, Considine J, Botti M. Unreported clinical deterioration in emergency department patients: a point prevalence study. Australasian Emerg Nurs J 2015;18(1):33-41.

[30] Sikka R, Mehta S, Kaucky C, Kulstad EB. ED crowding is associated with an increased time to pneumonia treatment. Am J Emerg Med 2010;28(7):809-12.

[31] Pines JM, Shofer FS, Isserman JA, Abbuhl SB, Mills AM. The effect of emergency department crowding on analgesia in patients with back pain in two hospitals. Acad Emerg Med 2010;17(3):276-83.

[32] Hong KJ, Shin SD, Song KJ, Cha WC, Cho JS. Association between ED crowding and delay in resuscitation effort. Am J Emerg Med 2013;31(3):509-15.

[33] Australian Council on Healthcare Standards (ACHS). Risk management \& quality improvement handbook. Ultimo: Australian Council on Healthcare Standards; 2013 15th March 2016. 81.

[34] Axelsson SB, Axelsson R. From territoriality to altruism in interprofessional collaboration and leadership. J Interprof Care 2009;23(4):320-30.

[35] Ferreira SMIL, Penteado MS, da Silva Júnior MF. Territory and territoriality in the hospital context: an interdisciplinary approach. Saude e Sociedade 2013;22(3):804-14. 